\title{
The advantage of the three dimensional computed tomographic (3 D-CT) for ensuring accurate bone incision in sagittal split ramus osteotomy
}

\author{
Coen Pramono D \\ Department of Oral Surgery \\ Faculty of Dentistry Airlangga University \\ Surabaya - Indonesia
}

\begin{abstract}
Functional and aesthetic dysgnathia surgery requires accurate pre-surgical planning, including the surgical technique to be used related with the difference of anatomical structures amongst individuals. Programs that simulate the surgery become increasingly important. This can be mediated by using a surgical model, conventional x-rays as panoramic, cephalometric projections and another sophisticated method such as a three dimensional computed tomography $(3 \mathrm{D}$-CT). A patient who had undergone double jaw surgeries with difficult anatomical landmarks was presented. In this case the mandible foramens were seen highly relatively related to the sigmoid notches. Therefore, ensuring the bone incisions in sagittal split was presumed to be difficult. A $3 D$-CT was made and considered to be very helpful in supporting the pre-operative diagnostic.
\end{abstract}

Key words: Three dimensional computed tomography (3D-CT), Sagittal split osteotomy, Accuration of Bone Incision

Korespondensi (correspondence): Coen Pramono D, c/o: Bagian Bedah Mulut, Fakultas Kedokteran Gigi Universitas Airlangga. Jln. Mayjen. Prof. Dr. Moestopo No. 47 Surabaya 60132, Indonesia.

\section{INTRODUCTION}

Various types of surgical techniques for correction of mandible progeny have been published. Since the introduction of the sagittal split ramus osteotomy (SSRO) of the mandible by Trauner and Obwegeser in $1957,{ }^{1} \mathrm{Dal}$ Pont in the year $1961,{ }^{2}$ and Obwegeser $1964,{ }^{3}$ the surgical combination technique of Obwegeser-Dal Pont has become the most popular method and is commonly used (Figure 1). This surgical technique has a very important step of a horizontal bone incision in the ascending ramus, specifically in the area located between the sigmoid notch and mandible foramen, therefore identification of this location is very important. Adequate space in that area should be available to ensure this procedure, in order to predict the amount of bone. An accurate imaging technique might be required to give a detailed form of the mandible including the position of the mandible foramens in relation to the sigmoid notches. A poor radiography result, such as shift of the x-ray apparatus tube, low sharpness or poor contrast may influence in the prediction during the surgical plan.

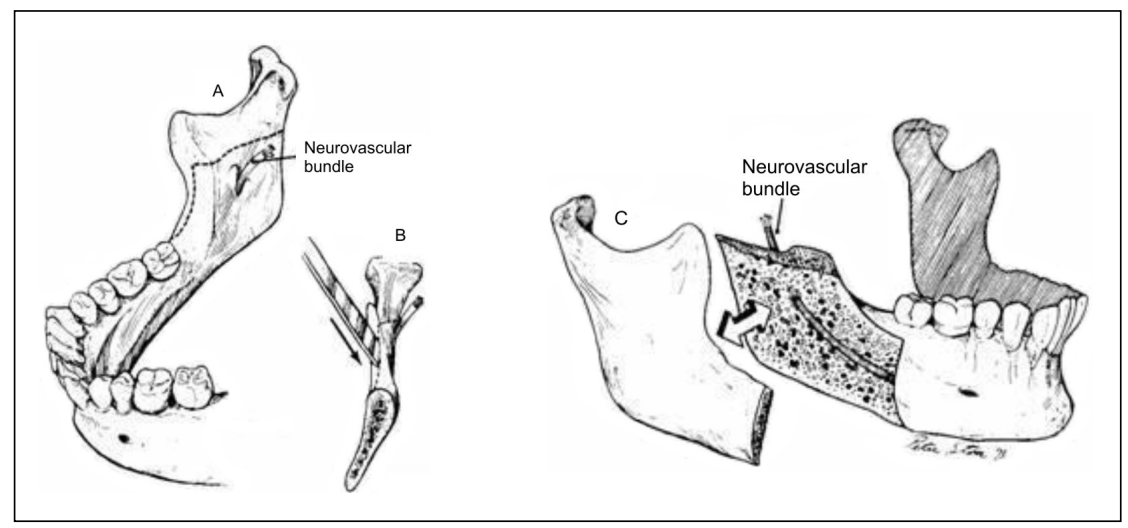

Figure 1. Technique for mandibular sagittal split osteotomy by Obwegeser-Dal Pont: A). This procedure requires precession in all aspects. The medial bony incision is made from anterior border to posterior border halfway through the mediolateral thickness of vertical ramus located between the sigmoid notch and mandible foramen; B). The ramus split with osteotomy; C) The split ramus is separated so that the inferior alveolar neurovascular bundle may be desected from proximal fragment. ${ }^{4}$ 
In the majority of cases a panoramic radiograph is usually sufficient. In some cases, where a more precise location of the mandible foramens needs to be clearly identified, the aid of more sophisticated radiography technique may be required, such as computed tomography (CT).

Three-dimensional (3-D) studies in medicine began in the early 1970 s presented by Ferencz and Graco. ${ }^{5} \mathrm{~A}$ computed tomography (CT) and 3-D reconstruction virtual reality surgical planning has been used in orthognathic surgery for various purposes, e.g. 3-D assisted simulation combining facial skeleton with facial morphology, ${ }^{6} 3-\mathrm{D}$ graphic demonstration of facial soft tissue changes in mandible progeny patients after a mandible sagittal split ramus osteotomy. ${ }^{7}$ A 3-D visualization may provide a surgeon with reality recognizable of shape of bone for precise surgical planning and simulation. ${ }^{5-13}$

\section{CASE}

A problem arose in a case of a 20-year-old female presented with dento-facial deformation and for surgical correction. Her primary concerns included an unaesthetic face due to mandible progeny as well as pain in her TMjoint. Clinical and cephalometric evaluations by an orthodontist concluded a case of Class III malocclusion and a maxillary hypoplasia.

A routine surgical procedure was planned and a panoramic radiography was used guiding the surgical judgment. The mandible evaluation of the medial ascending ramus showed unavailable spaces between both sigmoid notches and the mandible foramens (Figure 2a). The spaces available in the area between foramens and sigmoid notches are necessary, as the bone incision for performing a bilateral-SSRO (BSSRO) are took place in these areas.

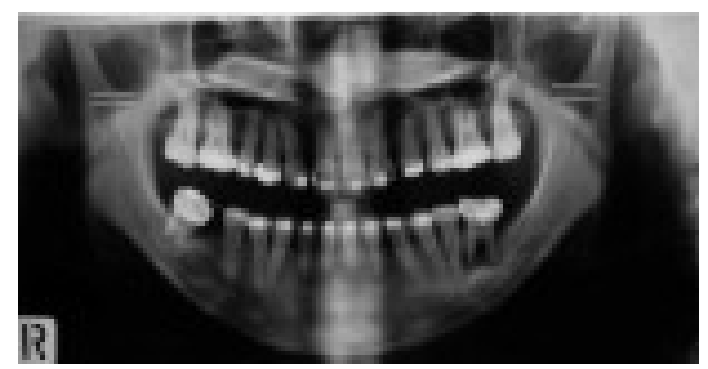

Figure 2a. Panoramic radiograph show narrow spaces between the sigmoid notch and mandible foramen in both sites.

\section{CASE MANAGEMENT}

Taking account of the panoramic radiography, a BSSRO with the surgical modification technique from Obwegeser-Dal Pont, seemed impossible to ensure. A 3-D CT was made to ensure a precise location between the foramens and sigmoid notches. In this projection showed differ with that what given in panoramic radiograph, a narrow spaces located in between the foramens and the sigmoid notches in both ascending ramus, were seen enough for performing a bone incision (Figure 2b).

Pre-operative surgical orthodontic treatment was done a period of one year. Pre-surgical cephalometric and clinical analysis concluded a Le Fort I osteotomy for reposition of the maxilla, $5 \mathrm{~mm}$ forward, and a mandible set back of $6 \mathrm{~mm}$ were necessary. A surgical model analysis and acrylic splint for occlusal guidance were also made to ensure the position of both upper and lower jaws.

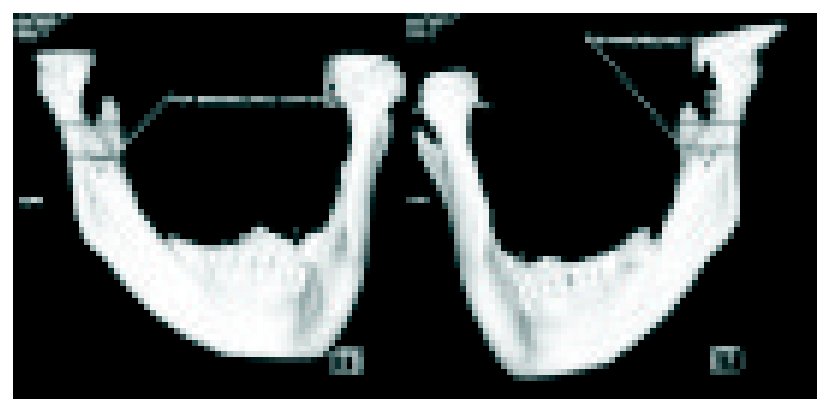

Figure 2b. The result of 3D-CT presented available spaces for bony incision line between sigmoid notches and mandible foramens in both sites.

Surgical treatment included a Le Fort I osteotomy as proposed by some authors was done. ${ }^{13-17}$ A BSSRO of the mandible using a combination technique of ObwegeserDal Pont were performed after a secure location for the first horizontal bone incision was found by a 3-D CT guidance. ${ }^{1-4}$ Difficulties were also present during the surgery in located of the area between sigmoid notch and mandible foramen in both sites due to the narrow spaces available in that areas. The surgery was done with no complication as it was guided by the 3D-CT.

\section{DISCUSSION}

In BSSRO cases, a panoramic radiograph is usually used for assisting the surgical procedure. More detailed anatomical landmarks sometimes require to be displayed at a high resolution of radiograph as this allowing a better understanding of the anatomical landmarks. In this case, a conventional radiograph was not adequate and sufficient for pre-surgical planning guidance. A poor position of the head or the shifting of the x-ray tube apparatus during taken the panoramic photograph may result in the mandible foramens being seen very high on the ascending ramus.

In this case, the mandible foramens was predicted to be high in relation to the sigmoid notches, therefore a 3-D CT was made. Through this medium the mandible bone surfaces and structures can be displayed clearly. 
Precise diagnosis and treatment planning of patients who need orthognatic surgery is necessary. Careful consideration of the anatomical landmarks should be noted as to the possibility of a different anatomical structure amongst different individuals.

Panoramic radiographs analysis integrated with a 3DCT reconstruction proved have an advantage to quantify the amount of space between the mandible foramens and the sigmoid notches. This procedure had tremendous potential for aiding in planning the surgical procedure more accurately, and thus the risk of alveolar nerve injury was reduced.

In conclusion, in certain cases of patients who need for undergo BSSRO a standard projection of radiography might not enough in supporting the surgical planning, and more sophisticated radiography technique might be needed.

\section{REFERENCES}

1. Trauner R, Obwegeser H. The surgical correction of mandibular prognatism and retrognathia with concideration of genioplasty: Surgical procedures to correct mandibular prognathism and reshaping the chin. Oral Surg Oral Med Oral Pathol 1957; 10: 671-92.

2. Obwegeser HL Indication for surgical correction of mandibular deformity by sagittal spiltting technique. Br J Oral Surg 1964; 50: 157.

3. Dal Pont. Retromolar osteotomy for correction of prognathism. J Oral Surg 1961; 19: 42-7.

4. Kruger OK. Textbook of oral surgery. $4^{\text {th }}$ ed. St Louis: CV Mosby Co; 1974. p. 491.

5. Xia J, Samman N, Yeung RWK, Shen SG, Wang D, Ip HHS, Tideman $H$. Three dimensional virtual reality surgical planning and simulation workbench for orthognathic surgery. The Int J Adult Orthod and Orthognath Surg 2000; 15: 265-82.
6. Liang HC, Wen HC. Three-dimensional computer-assisted simulation combining facial morphology for orthognathic surgery. Int J Adult Orthod Orthognath Surg 1999; 14(2): 140-5.

7. Techalertpaisarn P, Kuroda T. Three-dimensional computergraphic demonstration of facial soft tissue changes in mandibular prognathic patients after mandibular sagittal ramus osteotomy. Int J Adult Orthod Orthognath Surg 1998; 13(3): 217-25.

8. Altobelli DE, Kikinis R Mulliken JB, Cline H, Lorensen W, Jolesz F. Computer-assisted three dimensional planning in craniofacial surgery. Plast Reconstr Surg 1993; 92: 576-85.

9. Carls FR, Schuknecht B, Sailer HF. Value of three-dimensional computed tomography in craniomaxillofacial surgery. J Craniofac Surg 1994; 5: 282-88.

10. Fuhrmann RA, Frohberg U, Diedrich PR. Treatment prediction with three-dimensional computer tomographic skull models. Am J Orthod Dentofac Orthop 1994; 106: 156-60.

11. McCance AM, Moss JP, Fright WR, Linney AD, James DR. Threedimensional analysis techniques-Part 1: Three dimensional softtissue analysis of 24 adult cleft palate patients following Le Fort I maxillary advancement: A preliminary report. Cleft Palate Craniofac J 1997; 34: 36-45.

12. Southard TE, Morris JH, Couthard KA, Zeitler DL. A Threedimensional system for planning orthognathic surgery. J Am Dent Assoc 1994; 125: 452-60.

13. Vannier MW, Marsh JL, Warren JO. Three-dimensional CT reconstruction images for craniofacial planning and evaluation. Radiology 1984; 150: 179-84.

14. Bell WH, Mannai CH, Luhr HG. Art and science of the Le Fort I downfracture. International Journal of Adult orthodontics and orthognathic surgery 1988; 1: 23-52.

15. Reyneke JP, Masureik CJ. Treatment of maxillary deficiency by a Le Fort I osteotomy downsliding technique. J Oral Maxillofacial Surg 1985; 43: 914-6.

16. Perssonn G, Hellem S, Nord PG. Bone-plates for stabilizing Le Fort I osteotomies. J Maxillofacial Surgery 1986; 14: 69-73.

17. Profit WR, Phillips C, Prewit JW, Turvey TA. Stability after surgical orthodontic correction of skeletal Class III malocclusion. II. Maxillary advancement. Int J Adult Orthod Orthognath Surg 1991; 6: 71-80. 